\title{
An Extended Logistics Model with the Theory of Constraints: Applying TOC in Telecom Industry
}

\author{
Shenghan Zhou' and Fajie Wei ${ }^{2}$ \\ 'Economics and Management Center for National Defense, Beihang University, Beijing \\ 100083, P.R. China \\ ${ }^{2}$ Economics and Management School of Beihang University, Beijing 100083, P.R. China \\ Godbus@sem.buaa.edu.cn Weifajie@buaa.edu.cn
}

\begin{abstract}
The telecommunication industry depends on unit level mobility to respond to unexpected demands occurring over a large geographical range. If the response is not timely and comprehensive, these units may fail to meet the customer' required. Therefore, many telecom enterprises prepared abundant spare part. The arrangement provides "timely and wonderful" service while they raise the debt-to-asset ratio to an uncompromisable level. However, the classical ERP system is far less effective in the service industry, especially in telecom. The first problem comes from the business process, the finance department debate any fixed assets is in their authority. Another problem is the risk to attempt to reduce the stock of the spare part. To make the solution, the study redefined the concept of stock and the fixed assets in telecom industry, firstly. Then the study developed an extended logistics model according to aforesaid definition. In the definition, any assets which may be redeployed belong to the stock, instead of fixed assets. And the business process was reengineered to transfer the authority of stock management to the extendedlogistics department. To improve the effect of the model, the study applies the theory of constraints. The application of the model makes a good performance.
\end{abstract}

Keywords: TOC, Service industry, Business process, Workflow

\section{INTRODUCTION}

The theory of constraints comes from the introduction of optimized production timetables scheduling software [1]. Goldratt [2] furnishes an excellent accounting of the evolution of his thinking. And the TOC encompass three interrelated areas: logistics/production, performance measurement, and problem solving/thinking tools [3]. The critical chain concept remained unstudied until Goldratt's Critical Chain appeared in 1997[4]. Umble and Srikanth [5,6] believe buffers maintain a small amount of inventory used to protect due date performance.

The CNC Co, Ltd is the main ISP of China. In the operation, different operating units all follow the long-term operating methods. Under this model of operation, the logistics system works slow and ineffective. However, the cut-throat market competition environment leads to the rapid reaction ability of the telecom industry

Please use the following format when citing this chapter:

7hou, S., Wei, F., 2007, in IFIP International Federation for Information Processing, Volume 254, Research and Practical Issues of Enterprise Information Systems II Volume 1, eds. I. Xu, Tjoa $\Lambda$.. Chaudhry S. (Boston: Springer). pp. 657-662. 
faced to the changing market. In order to solve this problem, this study begins with the logistics model as well as its management system, and makes a study of the mechanism of logistics and spare part. Meanwhile, through the study of the buffer of bottleneck links in logistics system, the application of the model has improved a lot. The result of the research has indicated that the application of the model can save a great deal of outstanding funds for spare part, simultaneously it can reduce the debtto-asset ratio in an effective way.

\section{EXISTING LOGISTICS MODEL AND MANAGEMENT SYSTEM}

The existing logistics model as well as its management system has included two main aspects: the logistics mechanism and the spare part mechanism. There the logistics mechanism mainly includes the internal circulation process and management system of logistics in the operating units. While the spare part mechanism mainly covers the reasonable quantity of spare part stored by the two levels-central nodes and sub nodes everywhere in the service system, which is to satisfy the needs of maintenance and substitution in the inventory system.

\subsection{The Problem in the Existing Logistics System}

During the practical operation of the telecom operator, reasonable inventory has played a role of buffer. It can also shorten the logistics activity and accelerate reaction speed of operator faced to market. All allocating work must follow the decision of the financial department. Accordingly, there exists contradiction between the utilizing department and the purchasing center .In addition, the lengthy process of logistics results in the low reaction speed of the EPR, therefore the logistics efficiency has been reduced by a large margin. As a result, there exists an enormous gap between the better service to customers and the increasingly climbing cost.

\subsection{The Spare Part Management System}

The telecom operator has a variety of inventory; generally speaking, the materials are divided into four types. According to the study of Liu Hong Wei et. al, these materials are usually managed in accordance with two levels : central nodes of purchasing and regional units demanding the materials[7]. The distributing proportion is about $40 \%$ in sub node and the left in center. In order to guarantee the normal operation of the EPR and service, the study has to maintain a certain number of inventories. However, the traditional inventory with large quantities and multivarieties increases the cost of inventory and the complexity of management with no doubt. The inventory is usually stored and managed according to two levels-the central node and regional sub-node. However, because of the different service scope, 
An Extended Logistics Model with the Theory of Constraints: Applying TOC in Telecom

Industry 659

as to different sub-nodes, the emphasis over management also vary in some extent. In this way, the contradiction between the nodes with different levels occurs.

\section{EXTENDED LOGISTICS MODEL WITH TOC}

In order to solve the first problem, this study develops an expanded logistics model. This model emphasizes a new classification of the existing inventory materials. According to the internal survey of $\mathrm{CNC}, 95 \%$ of spare part in sub-nodes has never been used until scrapped in the year of 2005. The spare part is considered as fixed assets. The transfer of spare part becomes very complicated. The method is that the spare part is subdivided into two types-core spare part and secondary spare part, each with different storage proportion. Simultaneously, in order to redress the bias, we have to establish a reasonable set of calculating system to balance the proportion between central nodes and sub-nodes in spare part. Under this situation, it actually amounts to increase a reasonable buffer to the spare part before the core service ability. The specific calculating method of buffer will be introduced in detail in section 4 . The model makes a good performance as shown the Table1.

Table 1. The Improved Ascription of Different Logistics Type

\begin{tabular}{lcc}
\hline & Stored in sub-nodes & Stored in center \\
\hline Logistics materials & $40 \%$ & $60 \%$ \\
spare part & $60 \%$ & $40 \%$ \\
Market type logistics & $15 \% \sim 40 \%$ & $60 \% \sim 85 \%$ \\
Consumables & $40 \%$ & $60 \%$ \\
Logistics materials & $5 \% \sim 10 \%$ & $90 \% \sim 95 \%$
\end{tabular}

To make sure that the company can restore problems occurred to it promptly, study must regulate the allocating scope of each sub-node beforehand. It has already been realized, the system allocates the spare part according to two mechanisms. In the demonstration, the average time which the sub-point gets the required spare part from center node is about 3.5 hours. And the time from other neighbor sub-point is only about 1.8 hours.

\section{EXPLOITING THE SYSTEM CONSTRAINT}

The model above has improved the old logistics system as far as the process and definition aspects concerned. However, how to measure the ratio of spare part in the 
expanding model has become a new difficulty. In order to measure the ratio of spare part effectively, this study has revised the service model.

\subsection{Improve the Existing Service System}

In the standard service, system is divided into two parts-pretreatment and service centers. There the pretreatment includes two service requirements, and the service center makes separate response to the result of pretreatment. In order to guarantee the normal operation, traditional service system has prepared large numbers of spare part. In fact, the study by Cui Rongchun [8] had pointed out that the ratio of practical failure in most equipment is very low; therefore, this mechanism of spare part is ineffective. Accordingly, we have revised the spare part mechanism of the standard service model. The spare part mechanism which has already been revised happens to be a part of the expanding logistics system illustrated before. In figure 1, spare part is subdivided into the core spare part and the secondary spare part. While the potential service ability of the core spare part is considered as the buffer of the service center.

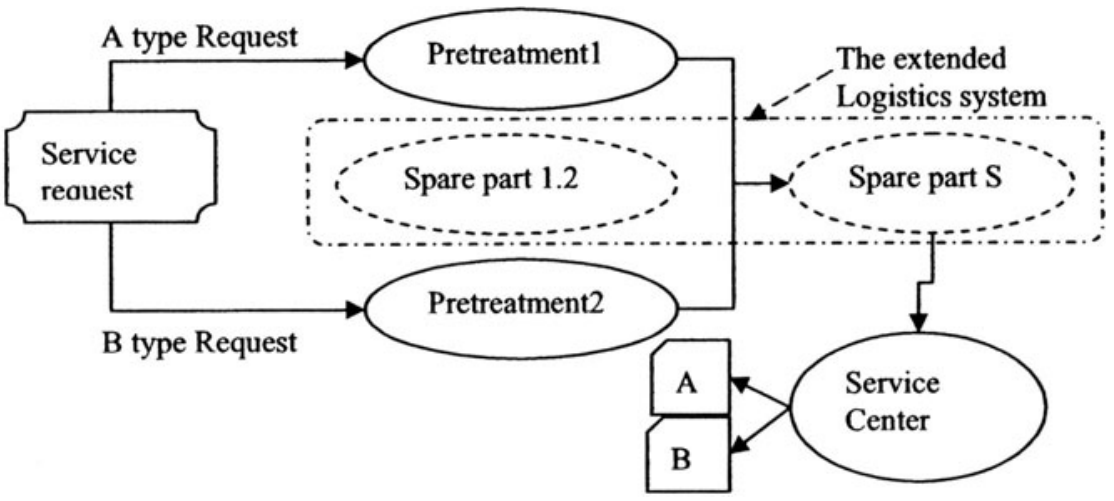

Figure 1. The Extended Service System Model

\subsection{The Computation of the Spare-part Buffer}

It is shown in Figure 1, there are two equipments to pretreat the services request; they are named pretreatment 1 and 2 . And there is a service center to provide the service to different result of pretreatment. It is assumed that pretreatmentl may meet the problem with the probability of the negative exponential distribution [9]. The planning service cycle is defined as $T . F(t)=1$-eft (f-the probability of problem), $H(t)$ $=1-\mathrm{e}-\mathrm{ht}$ ( $\mathrm{h}$ - the probability of repaired). Some parameters display as:

I-Inventory buffer, $h(t)$-pretreatment 1 's distributing function of repair time. WbThe average loss of center for repair pretreatment, CI- the cost of every Inventory Unit,P1- Pretreatment1 product of every time unit, P2- Pretreatment2 product of every 
An Extended Logistics Model with the Theory of Constraints: Applying TOC in Telecom Industry 661 time unit, Pa-product of every time unit of service $A, P_{b}$-product of every time unit of service B. T1- Adjust time of provide service A, T2- Adjust time of provide service B

When the pretreatment equipmentl fails to service, the average repaired time will be $t(t<=T)$. The average space between two continuous problems will be $u(u<=T)$.

$$
\begin{aligned}
& t=\int_{0}^{L} t d H(t)=\int_{0}^{L} t d\left(1-e^{-h t}\right)=\frac{1}{h}\left(1-e^{h t}\right)-L e^{-h t} \\
& u=\int_{0}^{L} t d F(t)=\int_{0}^{L} t d\left(1-e^{f t}\right)=\frac{1}{f}\left(1-e^{-f t}\right)-L e^{-f t}
\end{aligned}
$$

We suppose the center will fail to serve the A type service request when the pretreatment equipment 1 meet some problem. Then the probable waste time was set as $T_{0}$. There are two cases of the service system while the pretreatment equipment 1 fails to service.

The average loss of service center is:

$$
\begin{aligned}
& \mathrm{W}_{\mathrm{h} 1}=\mathrm{W} \int_{\max \left(\frac{1}{\mathrm{P}_{2}}, T_{2}, \frac{1}{P_{t}},\right.}^{\mathrm{T}}\left(t-\max \left\{\frac{\mathrm{I}}{\mathrm{P}_{\mathrm{a}}}, T_{2}+\frac{I}{P_{h}}\right\}\right) h(t) d t \\
& \mathrm{~W}_{\mathrm{b} 2}=\mathrm{W} \int_{\max \left\{\frac{1}{\mathrm{P}_{\mathrm{b}}}, T_{1}, \frac{1}{P_{\mathrm{o}}}\right.}^{\mathrm{T}}\left(t-\max \left\{\frac{\mathrm{I}}{\mathrm{P}_{\mathrm{b}}}, T_{1}+\frac{I}{P_{a}}\right\}\right) h(t) d t
\end{aligned}
$$

Then the cost of inventory is: $\mathrm{Cl}=\mathrm{CII}+\mathrm{W}_{\mathrm{b} 1} / \mathrm{u} \quad \mathrm{C} 2=\mathrm{CI}+\mathrm{W}_{\mathrm{b} 2} / \mathrm{u}$. And the possible cases may include four results:

$$
\frac{\mathrm{I}}{\mathrm{P}_{\mathrm{a}}} \leq T_{2}+\frac{I}{P_{h}} ; 2 . \frac{\mathrm{I}}{\mathrm{P}_{\mathrm{a}}} \geq T_{2}+\frac{I}{P_{b}} ; 3 . \frac{\mathrm{I}}{\mathrm{P}_{\mathrm{h}}} \leq T_{1}+\frac{l}{P_{a}} ; 4 . \frac{\mathrm{I}}{\mathrm{P}_{\mathrm{h}}} \geq T_{1}+\frac{I}{P_{a}}
$$

It is able to get four possible buffer inventories from these cases, B1, B2, B3, B4. And the best buffer inventory is $\max \{\min (\mathrm{B} 1), \min (\mathrm{B} 2), \min (\mathrm{B} 3), \min (\mathrm{B} 4)\}$. In fact, the really application get the $120 \%$ inventory of the result.

\section{CONCLUSIONS}

The expanding logistics model illustrated in this journal is based on the TOC, it is an improvement of the purchasing and logistics department in traditional telecom industry. The improvement has mainly includes two aspects: 1.an expansion of function of the logistics system; 2.an improvement to the circulation mode of logistics. This study also discusses the calculation of the crucial spare part buffer existing in the improved logistics system. In the future, the predictable study approach is centered on the further discussion about the developing and operating mechanism of buffer that existing in the telecom service system.

\section{REFERENCES}

1. E.M. Goldratt and J. Cox, The Goal (North River Press: Croton-on- Hudson, NY, 1984).

2. E.M. Goldratt, Computerized shop floor scheduling, International Journal of Production Research. Volume 26, Number 3, pp.443-455, (1988). 
3. Spencer, M.S., Cox III, J.F., Optimum production technology (OPT) and the theory of constraints (TOC): analysis and genealogy, International Journal of Production Research. Volume 33, pp.1495-1504, (1995).

4. E.M. Goldratt, Critical Chain (North River Press: Great Barrington, MA, 1997).

5. K.R. Graham, Critical chain: the theory of constraints applied to project management, International Journal of Project Management. Volume 18, pp.173-177, (2000).

6. M. Umble and M.L. Srikanth, Synchronous Manufacturing: Principles for World Class Excellence (Spectrum Publishing Company: Wallingford, CT, 1995).

7. H. Liu, The study on the optimization of inventory management in telecom industry, china storage \& transport magazine. Volume 3, pp.104-106, (2006).

8. R. Cui, The study on the optimization of spare part in telecom industry, Telecommunications Technology. Volume 3, pp.83-85, (2006).

9. R.C. Newbold, Project management in the fast lane: applying the theory of constraints. Boca Raton (The St. Lucie Press: 1998). 